\title{
Efisiensi Proses Produksi Batik Melalui Penerapan Mesin Pengering Batik Dan Kompor Pemanas Lilin Batik Semi Otomatis
}

\author{
Agung Prijo Budijono ${ }^{1}$, Wahyu Dwi Kurniawan² \\ 1,2 Jurusan Teknik Mesin, Universitas Negeri Surabaya \\ 1 agungbudijono@universitas.ac.id \\ 2wahyukurniawan@universitas.ac.id
}

\begin{abstract}
Abstrak-Permasalahan utama yang dihadapi UKM produsen batik yaitu pada saat musim hujan pasti mengalami kendala dan hambatan pada proses pengeringan batik tulis. Selama ini proses pengeringan batik tulis dilakukan secara konvensional yaitu dikeringkan dengan mengandalkan panas sinar matahari sehingga membutuhkan waktu relatif lama $( \pm 1,5$ jam $)$. Namun apabila cuaca dalam kondisi mendung atau hujan proses pengeringan bisa membutuhkan waktu 3-4 jam. Dengan kata lain pada saat mendung atau hujan produksi batik akan terhambat secara signifikan hal ini akan berakibat pelanggan akan sering komplain. Selain itu, untuk pemanas lilin batik masih menggunakan kompor gas konvensional yang suhunya tidak terkontrol, jika lilin batik terlalu panas maka kompor harus dimatikan dan jika lilin batik terlalu dingin maka harus menyalakan kembali sehingga kurang efisien. Target yang ingin dicapai dari kegiatan ini yaitu untuk meningkatkan efisiensi waktu proses pengeringan minimal 2 kali lebih cepat dari sebelumnya dan untuk meningkatkan efisiensi konsumsi LPG sebesar $\mathbf{2 5 \%}$ dari sebelumnya. Luaran kegiatan ini yaitu mesin pengering batik semi otomatis, kompor pemanas lilin semi otomatis dan publikasi ilmiah. Metode yang digunakan dalam mencapai tujuan tersebut yaitu dengan merancang, manufaktur, assembly dan menerapkan mesin pengering batik printing semi otomatis dan penerapan kompor pemanas lilin batik semi otomatis. Berdasarkan hasil kegiatan yang telah dilakukan, pihak mitra sangat bersyukur dengan adanya kegiatan ini karena usaha yang selama ini mereka rintis dapat berkembang lebih maju. Berdasarkan hasil uji fungsi yang telah dilakukan, maka dapat dikatakan bahwa mesin pengering batik semi otomatis dan kompor pemanas lilin batik semi otomatis dapat bekerja dengan baik dengan uraian sebagai berikut: (1) Suhu dalam ruang pengering dapat dikontrol sesuai kebutuhan $(\mathbf{5 0} \pm \mathbf{5}$ ${ }^{\circ}$ Celcius); (2) Proses pengeringan hanya membutuhkan waktu 1 jam yang tidak terganggu oleh cuaca; (3) Konsumsi gas LPG dalam sekali proses pengeringan sebesar 500 gr; (4) Suhu pemanas lilin batik dapat terkontrol dan terjaga sesuai kebutuhan $\left(125 \pm 2^{\circ} \mathrm{C}\right)$; dan (5) Konsumsi gas LPG pada proses pemanasan lilin menjadi lebih hemat $30 \%$, yang awalnya membutuhkan 80 gr/jam menjadi 50 gr/jam.
\end{abstract}

Kata Kunci-pengering, kompor, batik, otomatis, UKM

Abstract-The main problems faced by SMEs batik producers, namely when the rainy season is definitely having problems and obstacles in the process of drying batik. During the drying process is done in the conventional batik is dried with hot relying on sunlight so it takes a relatively long time ( \pm 1.5 hours). However, if the weather is cloudy or rainy drying process can take 3-4 hours. In other words, when cloudy or rainy batik production will be significantly hindered this will result in the customer will often complain. In addition, for heating wax batik still using conventional gas stove where the temperature is not controlled, if batik wax is too hot then the stove must be switched off and if the wax batik too cold then had to turn back so that less efficient. Targets of this activity is to improve the efficiency of the drying process time of at least 2 times faster than before and to improve the efficiency of LPG consumption by $25 \%$ from the previous. Outcomes of these activities are batik dryer machine semi automatic, semi-automatic wax heater stove and scientific publications. The method used to achieve these goals is by designing, manufacturing, assembly and apply a drying machine semi-automatic printing batik and batik wax application of heating stove semi-automatic. Based on the results of the activities that have been carried out, the partners are very grateful for this because the business activities for which they can develop more advanced path. Based on the test results of the functions that have been done, it can be said that the semiautomatic drying machine batik and batik wax heater stove semi-automatic can work well with the description as follows: (1) The temperature in the drying chamber can be controlled as needed (50 $\pm 5^{\circ}$ Celsius ); (2) The drying process takes about 1 hour which is not disturbed by the weather; (3) Consumption of LPG in a single process of drying at $500 \mathrm{~g}$; (4) batik wax heater temperature can be controlled and maintained as needed $(125 \pm 2$ ${ }^{\circ} \mathrm{C}$ ); and (5) LPG gas consumption in the process of heating the wax becomes more save $30 \%$, which initially require 80 grams / hour to $50 \mathrm{~g} / \mathrm{h}$.

Keywords — dryer, stove, batik, automatic, SMEs.

\section{Pendahuluan}

Desa Kenongo Kecamatan Tulangan Kabupaten Sidoarjo merupakan salah satu sentra industri pennghasil batik Sidoarjo selain Kampung Jetis. UKM mitra dalam kegiatan in yaitu UKM Batik Sari Kenongo dan UKM Batik Patrang Kencana. Berdasarkan hasil observasi dan diskusi dengan kedua UKM mitra, permasalahan utama yang dihadapi yaitu pada saat musim hujan pasti mengalami kendala dan hambatan pada proses pengeringan batik tulis. Selama ini proses pengeringan batik tulis dilakukan secara konvensional yaitu dikeringkan dengan mengandalkan panas sinar matahari sehingga membutuhkan waktu relatif lama $( \pm 1,5$ jam$)$. Namun apabila cuaca dalam kondisi mendung atau hujan proses pengeringan bisa membutuhkan waktu 3-4 jam. Dengan kata lain pada saat mendung atau hujan produksi batik akan terhambat secara signifikan hal ini akan berakibat pelanggan akan sering komplain. Selain itu, untuk pemanas lilin batik masih 
menggunakan kompor gas konvensional yang suhunya tidak terkontrol, jika lilin batik terlalu panas maka kompor harus dimatikan dan jika lilin batik terlalu dingin maka harus menyalakan kembali sehingga kurang efisien.

Suatu usaha baru bisa dikatakan produktif jika usaha tersebut dapat dilaksanakan secara efisien dan efektif, atau dapat menggunakan sumber daya yang seminimal mungkin dengan hasil yang seakurat mungkin. Jadi kalau ingin meningkatkan produktivitas suatu usaha dapat dilakukan dengan meningkatkan efisiensi dan efektivitas usaha tersebut.[8]

Ada beberapa cara yang dapat ditempuh oleh pengusaha untuk meningkatkan efisiensi dan efektivitas usahanya, antara lain: 1) Dengan meningkatkan skill atau keterampilan karyawannya, dan 2) Dengan memutakhirkan peralatan produksinya Cara yang disebut terakhir ini jarang ditempuh oleh pengusaha kecil. Hal ini disamping disebabkan karena keterbatasan modal, juga karena keterbatasan pengetahuannya yang pada umumnya belum bisa mengakses informasiinformasi terkini khususnya yang berhubungan dengan perkembangan peralatan produksi yang semakin canggih [3]. Lain halnya dengan cara yang biasa ditempuh oleh pengusahapengusaha yang sudah besar (profesional), mereka rata-rata lebih suka memilih cara untuk memutakhirkan peralatan produksinya guna meningkatkan efisiensi dan efektifitas usahanya [1].

Terlepas dari golongan pengusaha besar atau pengusaha kecil, maka sebelum menentukan langkah/cara yang akan ditempuh untuk meningkatkan efisiensi, pengusaha harus benar-benar mempertimbangkan dahulu cara yang akan ditempuh itu agar tidak justru malah merugi. UKM dalam Program Ini ini adalah pengusaha kecil yang memiliki problem seperti di atas, yakni ingin meningkatkan efisiensi dan efektivitas guna meningkatkan produktivitas usahanya. Pimpinan UKM juga menyadari bahwa hal ini dapat dilakukan dengan memutakhirkan peralatannya. Tetapi karena secara finansial belum mampu, serta pengetahuannya dalam bidang perkembangan peralatan produksi juga lemah, dan tidak punya inovasi untuk mengembangkan peralatannya, maka perlu dicari solusi yang tepat untuk memecahkannya.

Fuad menyatakan bahwa pada umumnya masalah produksi yang dihadapi oleh usaha kecil dan menengah (UKM) Indonesia tidak cocok bila dipecahkan melalui penerapan/penggunaan mesin-mesin yang berteknologi mutakhir/canggih, tetapi justru banyak yang lebih cocok dipecahkan melalui penerapan teknologi tepat guna (TTG). Sebab biaya investasi untuk penerapan TTG relatif murah, dan penguasaan teknologi tidak memerlukan ilmu pengetahuan yang terlalu tinggi [2].

Setelah diskusi intensif dangan dosen pengusul dari Unesa, pihak UKM mitra mengusulkan agar dibantu mendapatkan solusi untuk memecahkan masalah yang dihadapinya. Maka pada PKM Unesa melalui program IbM, UKM Batik Sidoarjo Sari Kenongo dan Patrang Kencana diusulkan untuk dibantu melalui penerapaan mesin pengering batik printing semi otomatis dan penerapan kompor pemanas lilin batik semi otomatis.
Diharapkan melalui program IbM ini, proses pengeringan kain batik menjadi lebih efektif dan efisien meski musim hujan tiba karena tidak tergantung lagi dengan panas sinar matahari. Kondisi ini sangat diinginkan oleh kedua UKM mitra, karena kontinuitas usaha dapat dijaga. Bila pelanggan semakin banyak maka akan berdampak pada meningkatnya pendapatan yang diperoleh UKM dan meningkatnya kesejahteraan, baik pengusaha ataupun karyawannya.

Target yang ingin dicapai dari kegiatan ini yaitu untuk meningkatkan efisiensi waktu proses pengeringan minimal 2 kali lebih cepat dari sebelumnya dan untuk meningkatkan efisiensi konsumsi LPG sebesar 30\% dari sebelumnya.

\section{METODE}

Metode pelaksanaan yang digunakan dalam kegiatan ini ditampilkan dalam bentuk flow chart pada Gambar 1. Untuk merancang dan membuat mesin pengering batik printing semi otomatis dan kompor pemanas lilin batik semi otomatis ini disusun dalam tahapan sebagai berikut:

- Tahap persiapan dan perancangan alat,

- Tahap manufaktur dan assembly mesin

- Tahap uji coba peralatan

- Tahap serah terima

- Tahap pemantauan, yang dilaksanakan sebanyak 3 tahapan untuk mengetahui keberhasilan dari pelaksanaan kegiatan ini.

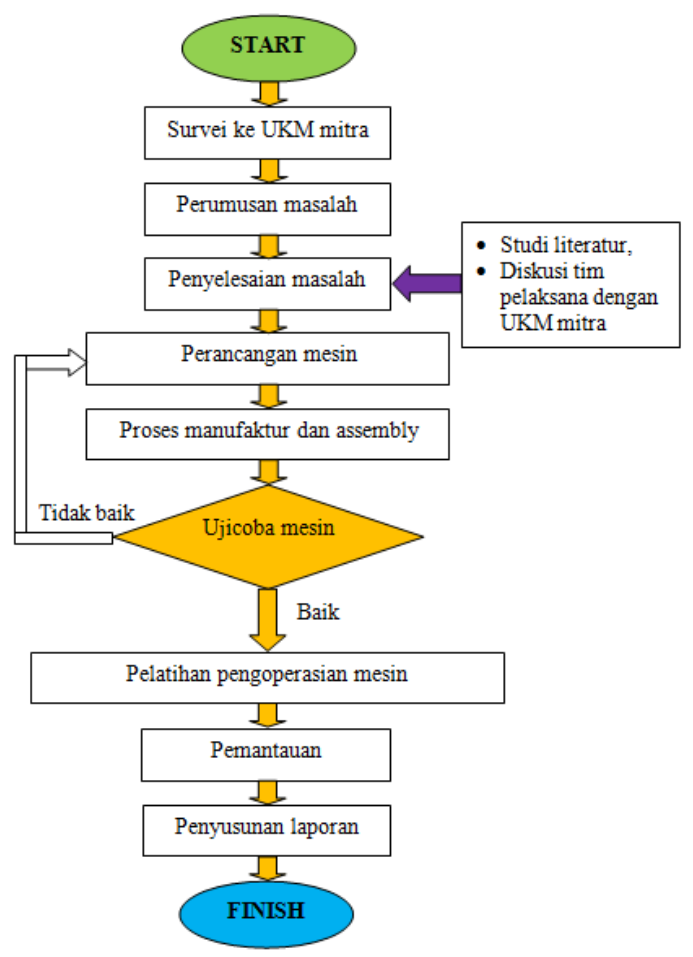

Gbr 1. Flow chart metode pelaksanaan 


\section{HASIL DAN PEMBAHASAN}

A. Hasil

Sebelum mewujudkan mesin pengering batik printing semi otomatis dan kompor pemanas lilin batik semi otomatis, tim pelaksana membuat diagram blok sistem kontrol dan desain mesin seperti yang ditampilkan pada Gambar 2 dan Gambar 3 berikut ini.

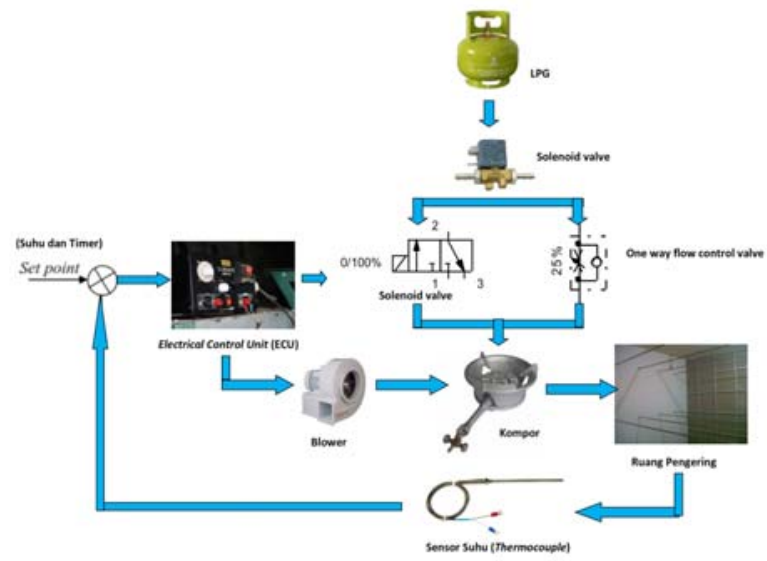

Gbr 2. Diagram blok alat pengering batik semi otomatis

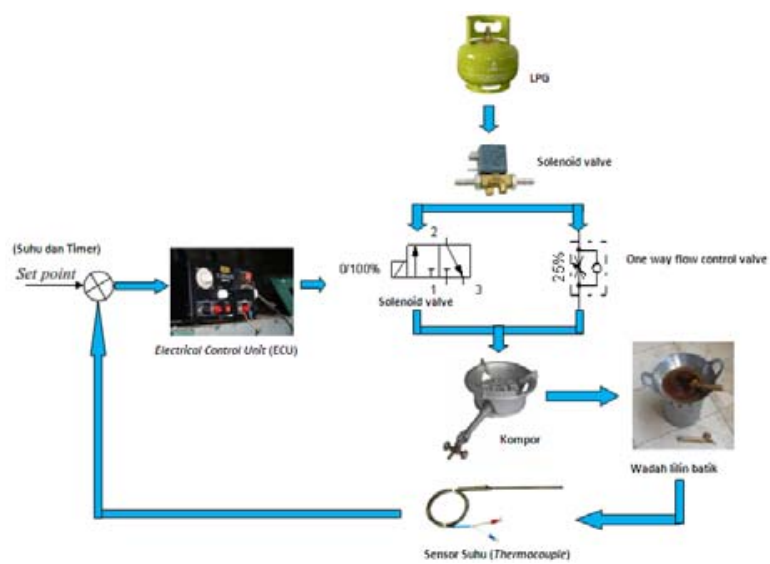

Gbr 3. Diagram blok alat kompor pemanas lilin batik semi otomatis

Berdasarkan hasil kegiatan yang telah dilakukan, tim pelaksana berhasil mewujudkan 2 unit mesin berbasis teknologi tepat guna berupa mesin pengering batik semi otomatis dan kompor pemanas lilin batik semi otomatis seperti gambar berikut.

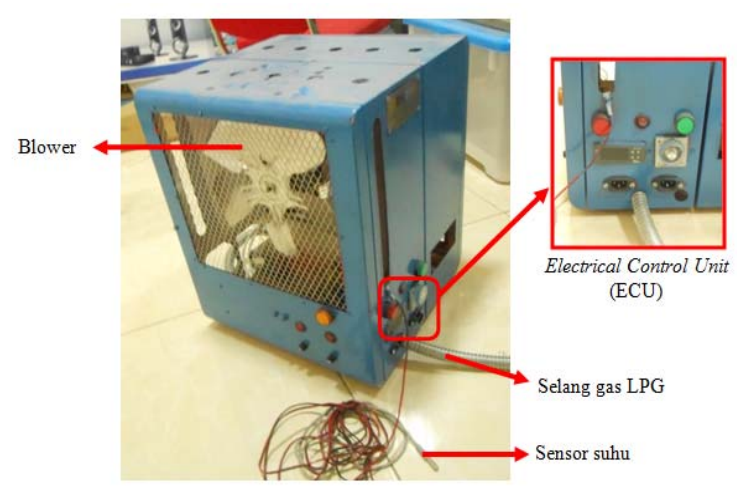

Gbr 4. Mesin pengering batik semi otomatis selesai dirakit

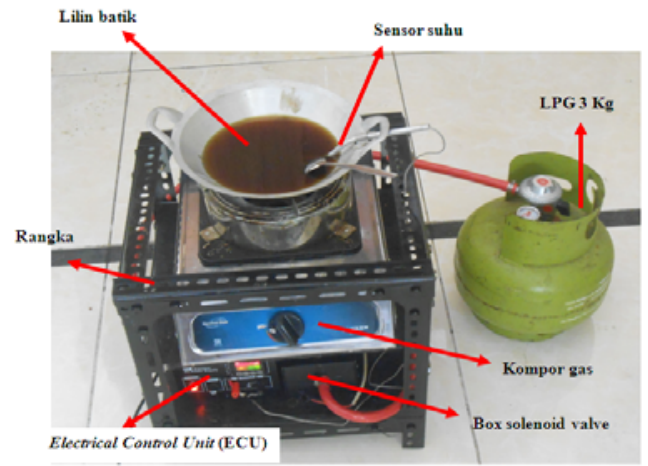

Gbr 5. Kompor pemanas lilin batik semi otomatis selesai dirakit

TABEL I

SPESIIKASI MESIN

\begin{tabular}{|c|l|l|l|}
\hline No. & $\begin{array}{c}\text { Spesifikasi } \\
\text { alat }\end{array}$ & $\begin{array}{c}\text { Mesin pengering } \\
\text { batik semi } \\
\text { otomatis }\end{array}$ & $\begin{array}{l}\text { Kompor pemanas } \\
\text { lilin batik semi } \\
\text { otomatis }\end{array}$ \\
\hline 1 & Dimensi & $(50 \times 50 \times 70) \mathrm{cm}$ & $(40 \times 40 \times 50) \mathrm{cm}$ \\
\hline 2 & Kapasitas & $\begin{array}{l}25 \quad \mathrm{~kg} / \text { proses } \\
\text { pengeringan }\end{array}$ & $400 \mathrm{gr}$ \\
\hline 3 & $\begin{array}{l}\text { Sumber } \\
\text { panas }\end{array}$ & LPG & $\mathrm{LPG}$ \\
\hline 4 & $\begin{array}{l}\text { Suhu } \\
\text { operasional }\end{array}$ & $50 \pm 5^{\circ} \mathrm{C}$ & $125 \pm 2{ }^{\circ} \mathrm{C}$ \\
\hline 5 & $\begin{array}{l}\text { Keselamatan } \\
\text { kerja }\end{array}$ & $\begin{array}{l}\text { Perlu perhatian khusus pada regulator } \\
\text { gas LPG dalam mengantisipasi } \\
\text { kebocoran gas }\end{array}$ \\
\hline
\end{tabular}

TABEL III

HASIL UJI FUNGSI MESIN

\begin{tabular}{|l|c|c|}
\hline \multicolumn{1}{|c|}{ Uraian } & $\begin{array}{c}\text { Mesin pengering } \\
\text { batik } \\
\text { semi otomatis }\end{array}$ & $\begin{array}{c}\text { Kompor } \\
\text { pemanas lilin } \\
\text { batik semi } \\
\text { otomatis }\end{array}$ \\
\hline Setting suhu pada ECU & $50^{\circ} \mathrm{C}$ & $125^{\circ} \mathrm{C}$ \\
\hline $\begin{array}{l}\text { Suhu terukur saat api } \\
\text { besar padam }\end{array}$ & $55^{\circ} \mathrm{C}$ & $127^{\circ} \mathrm{C}$ \\
\hline
\end{tabular}




\begin{tabular}{|l|c|c|}
\hline \multicolumn{1}{|c|}{ Uraian } & $\begin{array}{c}\text { Mesin pengering } \\
\text { batik } \\
\text { semi otomatis }\end{array}$ & $\begin{array}{c}\text { Kompor } \\
\text { pemanas lilin } \\
\text { batik semi } \\
\text { otomatis }\end{array}$ \\
\hline $\begin{array}{l}\text { Suhu terukur saat api } \\
\text { besar menyala kembali }\end{array}$ & $45^{\circ} \mathrm{C}$ & $123^{\circ} \mathrm{C}$ \\
\hline $\begin{array}{l}\text { Interval suhu terukur } \\
\text { saat alat bekerja secara } \\
\text { otomatis }\end{array}$ & $50 \pm 5^{\circ} \mathrm{C}$ & $125 \pm 2{ }^{\circ} \mathrm{C}$ \\
\hline Konsumsi bahan bakar & 500 gr/jam & 50 gr/jam \\
\hline Kapasitas & $25 \mathrm{~kg}$ kain & $400 \mathrm{gr}$ \\
\hline $\begin{array}{l}\text { Electrical Control Unit } \\
\text { dan sensor panas } \\
\text { (thermocouple) }\end{array}$ & $\begin{array}{l}\text { Baik } \\
\text { (Ketika sensor didekatkan pada } \\
\text { sumber panas, dapat mendeteksi } \\
\text { suhu dari panas tersebut yang } \\
\text { ditunjukan dengan angka yang } \\
\text { tampak pada layar ECU) }\end{array}$ \\
\hline Kompor gas & Baik \\
\hline Solenoid valve & $\begin{array}{l}\text { Baik (dapat membuka dan menutup } \\
\text { secara otomatis sesuai instruksi dari } \\
\text { ECU) }\end{array}$ \\
\hline
\end{tabular}

Cara kerja mesin pengering batik semi otomatis:

- Masukan dan rentangkan kain batik yang akan dikeringkan ke dalam ruang pengeringan dan tutup pintu dengan benar

- Pasang regulator pada tabung LPG

- Letakan thermocouple di dalam ruang pengeringan

- Sambungkan kabel power ECU ke sumber tegangan AC $220 \mathrm{~V}$

- Tekan saklar power ECU (Electrical Control Unit)

- Setting suhu pada ECU menunjuk angka $50^{\circ} \mathrm{C}$

- Nyalakan kompor LPG maka alat akan mulai bekerja untuk mengeringkan kain

- Periksa kain setiap 15 menit

- Jika sudah selesai digunakan, maka matikan kompor dan tekan saklar power ECU.

- Lepas kabel power ECU dari sumber tegangan AC 220V

Cara kerja kompor pemanas lilin batik semi otomatis:

- Masukan 400 gr lilin batik ke atas wajan

- Pasang regulator pada tabung LPG

- Sambungkan kabel power ECU ke sumber tegangan AC $220 \mathrm{~V}$

- Tekan saklar power ECU (Electrical Control Unit)

- Setting suhu pada ECU menunjuk angka $125^{\circ} \mathrm{C}$

- Nyalakan kompor LPG maka alat akan mulai bekerja untuk memanaskan lilin batik

- Jika sudah selesai digunakan, maka matikan kompor dan tekan saklar power ECU.

- Lepas kabel power ECU dari sumber tegangan AC 220V

\section{B. Pembahasan}

Berdasarkan hasil kegiatan yang telah dilakukan, pihak mitra sangat bersyukur dengan adanya kegiatan ini karena usaha yang selama ini mereka rintis dapat berkembang lebih maju. Untuk mengetahui hasil lebih jelasnya, dapat dilihat pada tabel di bawah ini

TABEL IIIII

Hasil Sebelum dan Sesudah Program IbM Untuk Proses PENGERINGAN BATIK

\begin{tabular}{|l|l|l|}
\hline \multicolumn{1}{|c|}{ Uraian } & \multicolumn{1}{|c|}{ Sebelum } & \multicolumn{1}{c|}{ Sesudah } \\
\hline Sumber panas & Sinar matahari & Alat Pengering \\
\hline Kondisi cuaca & $\begin{array}{l}\text { Musim hujan } \\
\text { kesulitan }\end{array}$ & $\begin{array}{l}\text { Tidak terganggu } \\
\text { cuaca (terutama } \\
\text { digunakan pada } \\
\text { musim hujan) }\end{array}$ \\
\hline Waktu & $\begin{array}{l}1,5 \text { jam (musim } \\
\text { panas) } \\
3-4 \text { jam (musim } \\
\text { hujan) }\end{array}$ & $\begin{array}{l}1 \text { jam (semua } \\
\text { musim) }\end{array}$ \\
\hline Kapasitas & 25 kg kain/jam & $25 \mathrm{~kg}$ kain/jam \\
\hline
\end{tabular}

TABEL IVV

Hasil SEbelum dan SESUDAH Program IBM untuk Proses PEMANASAN LILIN BATIK

\begin{tabular}{|l|l|l|}
\hline \multicolumn{1}{|c|}{ Uraian } & \multicolumn{1}{|c|}{ Sebelum } & \multicolumn{1}{c|}{ Sesudah } \\
\hline Suhu kompor & Tidak terkontrol & $\begin{array}{l}\text { Terkontrol } 125 \pm 2 \\
{ }^{\circ} \mathrm{C}\end{array}$ \\
\hline $\begin{array}{l}\text { Cara } \\
\text { pengoperasian } \\
\text { pengaturan } \\
\text { suhu }\end{array}$ & $\begin{array}{l}\text { Manual (hanya } \\
\text { perkiraan) }\end{array}$ & $\begin{array}{l}\text { Otomatis (dapat } \\
\text { menyesuaikan } \\
\text { suhu sendiri) }\end{array}$ \\
\hline $\begin{array}{l}\text { Konsumsi } \\
\text { bahan bakar }\end{array}$ & $80 \mathrm{gr} / \mathrm{jam}$ & $50 \mathrm{gr} / \mathrm{jam}$ \\
\hline
\end{tabular}

\section{KESIMPULAN}

Berdasarkan hasil implementasi mesin yang telah dilakukan di UKM mira, maka dapat dikatakan bahwa mesin pengering batik semi otomatis dan kompor pemanas lilin batik semi otomatis dapat bekerja dengan baik dengan uraian sebagai berikut: (a) Suhu dalam ruang pengering dapat dikontrol sesuai kebutuhan $\left(50 \pm 5^{\circ}\right.$ Celcius); (b) Proses pengeringan hanya membutuhkan waktu 1 jam yang tidak terganggu oleh cuaca; (c) Konsumsi gas LPG dalam sekali proses pengeringan sebesar $500 \mathrm{gr}$; (d) Suhu pemanas lilin batik dapat terkontrol dan terjaga sesuai kebutuhan $\left(125 \pm 2{ }^{\circ} \mathrm{C}\right)$; (e) Konsumsi gas LPG pada proses pemanasan lilin menjadi lebih hemat $30 \%$. Awalnya membutuhkan $80 \mathrm{gr} / \mathrm{jam}$ menjadi 50 $\mathrm{gr} / \mathrm{jam}$.

\section{REFERENSI}

[1] Biegel. J.E. 1998. Pengendalian Produksi, Suatu Pendekatan Kuantitatif. Terjemahan. Tarsito Bandung.

[2] Fuad, Ahmadi. 2001. Karakteristik Teknologi Tepat Guna balam Industri Skala Usaha Kecil dan Menengah di Jawa Timur. Makalah yang disampaikan dalam rangka pelatihan produktivitas usaha kecil di Unesa.Tanggal 26 Juli 2001 
[3] Haryono, dkk. 1999. Buku Panduan Materi KuIiah Kewirausahaan. Unipres UNESA Surabaya.

[4] L. Mott, Robert. 2004. Machine Elements in Mechanical Design. New Jersey: Pearson Education.

[5] L. Mott, Robert. 2009. Elemen-Elemen Mesin dalam Perancangan Mekanis. Yogyakarta: ANDI.

[6] Sato, G. Takeshi dan Sugiarto, N. 1999. Menggambar Mesin. Jakarta: PT. Pradnya Paramita.

[7] Sularso dan Suga, Kiyokatsu. 2004. Dasar Perencanaan dan Pemilihan Elemen Mesin. Jakarta: PT. Pradnya Paramita.

[8] Sutantra, I Nyoman. 2001. Produktivitas Sistem Produksi dan Teknloogi.Makalah yang disampaikan dalam rangka pelatihan produktivitas usaha kecil di Unesa.Tanggal 26 Juni tahun 2001.

[9] Sutiono. 2002. Produktivitas UKM di Jawa Timur. Makalah yang disampaikan dalam rangka pelatihan produktivitas usaha kecil di Unesa, Tanggal 26 Juni tahun 2002. 